\title{
Contexto dos berçários e um programa de intervenção no desenvolvimento de bebés
}

\author{
Nurseries environment and the intervention in babies' development
}

\author{
C.S. Almeida, N.C. Valentini
}

ARTIGO ORIGINAL | ORIGINAL ARTICLE

\begin{abstract}
O objetivo deste estudo foi investigar o contexto de berçários que atendesse a famílias de baixa renda e verificar o impacto de uma intervenção cognitivo-motora no desenvolvimento de bebés quanto à motricidade ampla, motricidade fina, linguagem e interação. Participaram do estudo 40 bebés, entre seis e oito meses, provenientes de dez berçários para famílias de baixa renda. As escolas foram agrupadas quanto à qualidade dos cuidados oferecidos; os bebés foram estratificados por gênero e aleatoriamente distribuídos em grupos interventivo $(n=20)$ e controle $(n=20)$. Foi utilizada uma ficha de observação para verificar a rotina dos berçários. A motricidade ampla e fina, a linguagem e a interação dos bebés foram avaliadas no pré e no pós intervenção. O programa de intervenção propiciou experiências de perseguição visual, manipulação de brinquedos e controle postural. Observaram-se restrições no espaço físico e nas oportunidades para brincar e interagir. Educadores centravam sua atenção no cuidado com higiene e alimentação dos bebés. Bebés provenientes de escolas com contextos mais apropriadas ao desenvolvimento apresentaram desempenhos superiores; e, a intervenção repercutiu positivamente no desenvolvimento global dos participantes. Em conclusão, ações educativas e estratégias interventivas devem ser implementadas nas creches, priorizando o processo de desenvolvimento infantil.

Palavras-chave: desenvolvimento infantil, creches, estimulação precoce
\end{abstract}

ABSTRACT

The aim of the study was to investigate nurseries environment for low-income families and verify the impact of a cognitive-motor skill intervention on babies' development in the large motor, fine motor, language and interaction. Participated in the study 40 babies, age between six and eight months, from ten nursery schools for low-income families. Schools groups were clustered according to the quality of the care offered; and the babies were stratify by gender and randomly assigned in intervention $(n=20)$ and control $(n=20)$ groups. The routine of the nurseries was investigated using an observational list. Babies' gross and fine motor skills, as well as interactions and language, were assessed at the pre and post-intervention. The intervention program provided activities such as visual tracking, toy manipulation and postural control. Results demonstrated restrict physical space, opportunities to play and interaction. Educators focus attention regarding to babies' hygiene and feed. Babies from schools with a more appropriate environment showed better performance; and the intervention influenced positively to participants' global development. As a conclusion, educative actions and intervention strategies must be implemented at nursery schools concern primarily with infant' development process.

Keywords: child development, child day care centers, early intervention

Submetido: 04.06.2012 | Aceite: 22.10.2012

Carla Skilhan Almeida, Nadia Cristina Valentini. Escola Superior de Educação Física, Universidade Federal do Rio Grande do Sul, Brasil.

Endereço para correspondência: Carla Skilhan Almeida, Escola Superior de Educação Física, Universidade Federal do Rio Grande do Sul, Rua Felizardo, 750 - Jardim Botânico, CEP: 90690-200 - Porto Alegre, RS, Brasil

E-mail: carlaskilhan@gmail.com 
O desenvolvimento é um processo no qual as mudanças são resultado de interações entre o indivíduo, envolvidos em uma ação, sendo influenciados por um ambiente, que pode ser enriquecido ou não, enfatizando a indissociabilidade da criança em desenvolvimento com o contexto em que está inserida (Bronfenbrenner, 2005). A qualidade dos primeiros anos de vida tem-se mostrado um importante preditor sobre o futuro da criança, tanto ao nível motor, como a locomoção, motricidade ampla, motricidade fina; ao nível cognitivo, como o uso da percepção, da memória, do raciocínio, da linguagem; e ao nível social, que se observam três elementos: (1) agentes sociabilizantes (envolvimento com pessoas mais significativas), (2) situação social do sujeito e (3) atributos pessoais (sujeito) (Almeida, Valentini \& Lemos, 2005; Besharov \& Marrow, 2006); período no qual a mediação de adultos é essencial ao desenvolvimento da criança (Carvalhares \& Benício, 2002). Com o ingresso da mãe no mercado de trabalho com uma jornada de 44 horas semanais, um grande número de crianças passa muitas horas do dia em berçários no Brasil (mais de oito horas/dia), segundo dados do Departamento Intersindical de Estatística e Estudos Socioeconômicos (DIEESE, 2007). Estima-se, no Brasil, que as taxas brutas de frequência à escola de alguns segmentos etários apresentaram crescimento relativo muito significativo. Para as crianças de 0 a 3 anos de idade, os percentuais dobraram de 1996 a 2006 , de $7.4 \%$ para $15.5 \%$. Na faixa seguinte, de 4 a 6 anos, as taxas passaram de $53.8 \%$ para $76.0 \%$, um aumento de mais de $20 \%$. Além disso, a desfasagem dos alunos do ensino fundamental caiu $41.6 \%$ em dez anos, segundo Instituto Brasileiro de Geografia e Estatística (IBGE, 2010).

Os cuidados com os bebés nos berçários enfatizam a higiene e alimentação; sendo a qualidade das experiências vivenciadas frequentemente negligenciada. As condições inadequadas são decorrentes da capacitação questionável dos funcionários e baixos salários dos educadores, da falta de equipamentos e espaço físico reduzido, do pouco incentivo a padrões adequados de interação e afetividade dos educadores em relação à criança (Almeida et al., 2005). Nos berçários, bebés ficam limitados às salas oito horas por dia, os menores permanecem mais tempo em cadeirinhas e os maiores são mantidos no chão. As interações com o meio são potencializadas somente para os que se deslocam de forma independente na experimentação de movimentos de controle postural (Almeida et al., 2005; Spessato, Valentini, \& Krebs, 2009). No entanto, pesquisa semelhante foi realizada e mostrou que o desenvolvimento dos bebés de berçário comparados com o desenvolvimento de bebés de abrigos e dos que ficam em casa com suas mães são melhores e respondem positivamente a uma intervenção motora (Almeida, 2010; Müller, 2008).

Oportunizar experiências que potencializem o desenvolvimento (Valentini, 2002, 2004; Valentini \& Rudsill, 2004), preparando educadores para intervir efetivamente com crianças, principalmente as que já evidenciam atrasos no desenvolvimento, se torna essencial para uma sociedade que pretende prevenir riscos sociais que culminam na pouca educação, no trabalho infantil, na negligência e no abuso parental (St.Pierre \& Rossi, 2006). Estudos sugerem que intervenções adequadas ao desenvolvimento promovem a melhoria no status de saúde (Almeida et al., 2005; Carvalhes \& Benício, 2002), o desenvolvimento e aquisição de habilidades (Almeida et al., 2005; Almeida, Paines \& Almeida, 2008; Valentini, 2002, 2004), e o auto conceito (Valentini \& Rudsill, 2004) na infância. Pesquisadores chamam a atenção para a necessidade de traçar estratégias interventivas e ações educativas que promovam a melhoria dos cuidados oferecidos para as crianças por familiares e por educadores nos berçários (Goubet, Rochat, Maire-Leblond, \& Poss, 2006; Vasconcelos, Aorim, Anjos, \& Ferreira, 2003), especialmente durante a primeira infância.

As seguintes hipóteses foram estabelecidas: (1) bebés atendidos em berçários com condi- 
ções mais apropriadas ao desenvolvimento demonstrariam desempenhos superiores quando comparados aos bebés provenientes de escolas com condições menos apropriadas; (2) bebés participantes da intervenção demonstrariam mudanças positivas do pré para o pós intervenção, enquanto para o grupo controle, mudanças positivas não seriam esperadas; (3) bebés participantes da intervenção demonstrariam desempenhos superiores no pós intervenção quando comparados aos seus pares do grupo controle.

Baseados nestas necessidades, este estudo teve como objetivos: investigar o contexto de berçários que atendesse a famílias de baixa renda e verificar impacto de uma intervenção cognitivo-motora no desenvolvimento de bebés quanto a motricidade ampla, motricidade fina, linguagem e interação.

\section{MÉTODO}

O presente estudo é do tipo experimental de delineamento experimental verdadeiro, de caráter descritivo e prospectivo.

\section{Participantes}

Participaram 40 bebés (entre seis e oito meses) provenientes de berçários que prestam serviços para famílias de baixa renda, segundo a Associação Brasileira de Empresa e Pesquisa [ABEP]. Das 128 escolas conveniadas com a prefeitura, 26 atendiam bebés menores de um ano. Dez escolas aceitaram participar do estudo. Foram incluídos bebés nascidos a termo, adaptados ao berçário por mais de duas semanas, que permanecem diariamente por sete horas ou mais, na rotina do berçário e não participantes de atividades específicas, ou seja, nenhuma atividade que se diferenciasse da rotina de alimentação, higiene e brincadeiras livre no chão, berço ou cadeiras. Também, como inclusão, os pais deveriam retornar o Termo de Consentimento informado assinado. Bebés com diagnóstico de problemas neurológicos não foram incluídos no estudo. Três bebés tiveram a participação descontinuada em decorrência de faltas na avaliação inicial. Os bebés foram estratificados por gênero e aleatoriamente distribuídos por sorteio simples em GI - Grupo Interventivo (número de participantes (n) igual a 20, média de idade $\left(M_{\text {idade }}\right.$ igual a 6.6 meses, desvio padrão $(D P)$ igual a 0.82 meses) e GC - Grupo Controle $\left(n=20, M_{\text {idade }}=6.6\right.$ meses, $D P=1.19$ meses). O número de participantes por grupo foi fundamentado em pesquisas prévias (Almeida et al., 2005; Almeida, 2010; Müller, 2008). A pesquisa foi guiada pelos critérios estabelecidos na Declaração de Helsínquia e aprovada pela Comissão de Ética da Universidade Federal do Rio Grande do Sul (processo 2003109).

\section{Instrumentos}

Uma Ficha de Observação da Rotina da Escola Infantil foi utilizada para descrever o contexto (Almeida et al., 2005) coletando informações sobre: escolaridade dos educadores do berçário e coordenadores, número e a rotina do pessoal envolvido com o bebé no diaa-dia, disponibilidade de brinquedos nas salas, oportunidades para brincar, instalações da escola, a adequação ao desenvolvimento do bebé, as preocupações com questões desenvolvimentistas dos bebés e outras observações que houvesse. A ficha foi sistematicamente preenchida durante as visitas às escolas e as observações transformadas em categorias com frequências.

Dois agrupamentos distintos de berçários foram formados, considerando a qualidade dos cuidados oferecidos ao bebé (Marques, Pelicioni \& Pereira, 2007): escolas com condições apropriadas ao desenvolvimento - ECAD (educadores com ensino médio ou superior, razão de um educador para até sete crianças, possuíam instalações para atividades extras e deixavam brinquedos à disposição das crianças) e escolas com condições inapropriadas ao desenvolvimento - ECID (educadores com ensino fundamental, razão de um educador para mais de sete bebés, não possuíam sala para atividades extras e não deixavam os brinquedos à disposição dos bebés). 
Para avaliar o desempenho dos bebés foi utilizada a Escala do Desenvolvimento do Comportamento da Criança no Primeiro Ano de Vida (Pinto, Vilanova \& Vieira, 1997). A escala, validada e normalizada para crianças brasileiras, é dividida em oito subescalas com 64 itens que envolvem comportamentos axiais e apendiculares (eixos somáticos corporais), comunicativo e não comunicativo (necessidade ou não de interação para realizar o comportamento), espontâneo e estimulado (necessidade ou não do estímulo para realizar o comportamento). Para o presente estudo os dados foram agrupados em categorias de acordo com sua especificidade. Motricidade ampla (MA): movimentos axiais espontâneos não comunicativos que envolvem atividades de deslocamento e postura. Motricidade fina (MF): movimentos apendiculares espontâneos e estimulados não comunicativos que envolvem atividades de perceber e explorar o objeto com as mãos e as atividades de manipulação e reconhecimento da sua função em determinada tarefa. Linguagem e interação (LI): movimentos axiais espontâneos comunicativos que envolvem atividades de emissão e repetições de sons. Durante a avaliação, pré e pós intervenção, os bebés foram filmados para posterior análise utilizando o processo duplo cego. Os avaliadores não possuíam conhecimento sobre a qual grupo pertenciam os bebés e em que período interventivo os bebés se encontravam.

\section{Procedimentos}

Um protocolo individualizado adequado à rotina do berçário foi implementado durante dez encontros, os quais não interferiram na rotina do sono e da alimentação dos bebés, ou seja, em momentos em que o bebé não estivesse com fome (pelo menos uma hora antes da alimentação), sono (longe da sua hora rotineira de sono - mais de duas horas de intervalo) e, em caso de indisposição, a intervenção não era realizada. As intervenções aconteciam três vezes por semana, 15 minutos por dia, conforme estudo prévio (Adalbjornson, 2001), Normalmente, os bebés chegavam ao berçário até oito horas da manhã, recebiam alimentação. A intervenção iniciava por volta de nove horas da manhã com cada bebé e terminava perto de dez horas. O almoço acontecia às onze horas e, o sono, as doze horas. O protocolo de intervenção, baseado em estudos prévios (Almeida et al, 2005; Müller, 2008) e adequados às condições das escolas garantindo a validade ecológica do estudo (Bronfenbrenner, 2005) consistia de atividades de: (1) perseguição visual (três minutos) a qual se caracterizava pelo acompanhamento visual do bebé de objetos em movimento a uma distância de aproximadamente 40 centímetros (Almeida et al., 2005); (2) manipulação de objetos variados (sete minutos) em função, forma, textura e peso (Rocha, Silva \& Tudella, 2006); (3) força, mobilidade e estabilização (cinco minutos) com atividades de controle de tronco, sentar, rolar, arrastar-se ou engatinhar e trocar decúbito (Goubet et al., 2006; Pinto et al., 1997). Um único examinador interagiu com os bebés, realizando as atividades na mesma sequência, num colchão no chão, com uma grande variedade de brinquedos (Almeida et al., 2005, Valentini, 2004). Após a estimulação, o bebé retornava para o berço, para a cadeirinha ou para o chão, conforme a rotina do berçário, controlando desta forma para variáveis intervenientes.

\section{Análise Estatística}

A análise dos dados foi realizada utilizando o software Statistical Package for the Social Sciences (SPSS) versão 17.0. Para investigar o contexto dos berçários e se as diferentes condições contextuais repercutiriam de maneira diferenciada no desenvolvimento dos bebés (desempenho) foram utilizadas estatísticas descritivas, testes $t$ para amostras independentes (comparações de grupo) e dependentes (comparações no tempo). Para comparar o impacto da intervenção no desenvolvimento (desempenho) dos bebés antes e após a intervenção em cada grupo foi aplicado o teste quiquadrado de McNemar. O nível de significância (p) adotado foi de $p \leq .05$. Quanto ao proce- 
dimento duplo-cego, o teste Kappa revelou um elevado índice de concordância entre avaliadores no pré (.75) e pós (1.00) intervenção.

\section{RESULTADOS \\ Contexto de berçários das Escolas Infantis}

Quanto à escolaridade dos educadores do berçário, apenas um educador estava cursando pedagogia. Em sete berçários, os educadores possuíam formação restrita a nível fundamental; os demais possuíam o certificado de nível médio completo. Os berçários poderiam ter mais de um educador por sala. Alguns educadores falavam um português coloquial, com erros silábicos, trocas de letras e erros na concordância verbal quando conversavam com os bebés e com os interventores. Isso foi aferido através da observação e registo em uma folha de rotina em todos os berçários avaliados, onde se registrava tudo o que acontecia no dia-a-dia dos bebés. Todos os coordenadores possuíam curso superior; em cinco escolas os coordenadores eram os próprios pedagogos e nas demais os coordenadores contavam com pedagogos que visitavam a escola esporadicamente. Em todas as escolas, coordenadores e pedagogos demonstravam preocupações com as questões desenvolvimentistas, mas, os educadores não têm em suas rotinas trabalhos específicos de estimulação motora com os bebés, embora tenham nos seus currículos de formação o conhecimento sobre tal. Eles necessitam de cursos de capacitação extra para colocar em prática tal conhecimento; embora a lei do estatuto da criança e do adolescente reforce essa importância de estimulação global do bebé (ECA - Lei Federal 8.069/1990 e Lei 9.394 da LDB).

Quanto à razão entre o número de bebés por educadores no cuidado diário, observou-se uma maior incidência de sete bebés para um educador (amplitude interquartis (Q3-Q1) foram seis para 11 bebés por educador). Em somente uma escola, uma educadora cuidava sozinha de 11 bebés. As rotinas dos educadores eram muito semelhantes. Até as oito e meia da manhã, todas as crianças já haviam chegado; recebiam a mamadeira e, imediatamente, iniciava-se a troca de fraldas. Enquanto os educadores realizavam esses atendimentos, os bebés ficavam sentados no "bebé conforto" ou deitados no berço. Poucos ficavam no chão. Por vezes, eram lhes alcançados brinquedos. Próximo das onze horas iniciava um processo semelhante para o almoço, seguido do sono do bebé e o reinício da rotina de alimentar e cuidar da higiene. Durante todo o dia, os educadores ficavam concentrados nas suas rotinas de alimentação e higiene, passando de um bebé para o outro, sem parar. Quando os bebés dormiam, os educadores envolviam-se com a organização e limpeza do ambiente.

Quanto às instalações, observou-se que apenas dois berçários tinham um ambiente externo para levar os bebés em dias secos e menos frios. Nenhuma escola tinha uma sala para bebés brincarem ou desenvolver atividades específicas. A grande maioria, com exceção de duas escolas que tinham uma sala de dormir, utilizava o mesmo espaço para alimentação, circulação, brinquedo e sono. Em muitos momentos, os bebés que estavam dormindo acordavam com o movimento proveniente das pessoas que circulavam no local, por ser um espaço pequeno e não específico para os bebés dormirem sem interrupção. Em quatro berçários um colchonete era colocado no chão, entretanto os bebés permaneciam nos berços e carrinhos espalhados neste único cômodo.

A quantidade de brinquedos nas salas e as oportunidades de brincar eram restritas, com um ou dois brinquedos, alocados em berços e carrinhos. $\mathrm{O}$ brinquedo era manipulado pelo bebé somente nos momentos que lhes eram oferecidos pelos educadores e/ou quando estavam em seu alcance tátil. Somente bichinhos de pelúcia e de borracha e argolas eram ocasionalmente oferecidos bebés. Dentre os dez berçários, quatro apresentavam brinquedos em caixas instaladas no próprio local. Todas as quatro escolas espalhavam os brinquedos no chão do berçário, mas apenas uma colocava os bebés em contato com os brinquedos. As seis outras escolas não colocavam brinquedos para 
os bebés, nem os tinham à vista (Tabela 1).

\section{Impacto Interventivo e Comparações nos grupos}

Nas comparações por agrupamentos dos berçários, os resultados evidenciaram que no pré intervenção os bebés que frequentavam ECAD demonstraram desempenho significativamente superior na MA $(p=.029)$, MF ( $p=$ .029) e IL $(p=.05)$, comparados aos bebés que frequentavam ECID. Esta tendência se manteve no pós intervenção para a MA $(p=.029) \mathrm{e}$ IL $(p=.029)$. Na motricidade fina, entretanto o desempenho dos grupos na pós intervenção foi semelhante $(p=.14)$. Quanto ao fator tempo, observou-se que do pré para o pós intervenção mudanças significativas foram observadas, tanto nas ECAD (MA $p=.012$, MF $p=.012$, IL $p=.017)$ quanto nas ECID (MA $p=.018$, MF $p=.023$, IL $p=.019$ ) (Tabela 2), pois nestas idades esse tipo de habilidade não é ainda esperado.

Nas comparações entre grupos interventivo e controle, os resultados sugerem que os bebés eram semelhantes na pré intervenção na MA, MF e IL. No pós intervenção, diferenças significativas foram observadas evidenciando desempenho superior do GI em relação ao GC. Quanto ao fator tempo, os resultados evidenciam mudanças positivas e significativas do GI do pré para o pós intervenção para a MA, MF e IL, enquanto para o GC mudanças significativas não foram observadas (Tabela 3 ).

\section{DISCUSSÃO}

\section{0 contexto}

Na maioria dos berçários, educadores com o ensino fundamental eram responsáveis pelo berçário. Os dados claramente sugerem que quanto menor o grau de instrução dos educadores, maiores eram as limitações na qualidade dos cuidados oferecidos.

Tabela 1

Característica do Contexto dos Berçários

\begin{tabular}{|c|c|c|c|c|c|c|c|c|c|c|}
\hline \multirow{2}{*}{ Características Contexto } & \multicolumn{10}{|c|}{ Berçários } \\
\hline & A & $\mathrm{B}$ & $\mathrm{C}$ & $\mathrm{D}$ & $\mathrm{E}$ & $\mathrm{F}$ & G & $\mathrm{H}$ & I & $\mathrm{J}$ \\
\hline \multicolumn{11}{|l|}{ Distribuição (n) dos bebés por escola } \\
\hline Grupo Interventivo & 3 & 2 & 1 & 1 & 3 & 3 & 3 & 2 & 1 & 1 \\
\hline Grupo Controle & 2 & 1 & 1 & 2 & 3 & 3 & 4 & 1 & 1 & 2 \\
\hline \multicolumn{11}{|l|}{ Nível de escolaridade dos educadores do berçário } \\
\hline \multicolumn{11}{|l|}{ Superior } \\
\hline Médio & & 1 & & 1 & 1 & & & & & \\
\hline Fundamental & 1 & & 1 & & & 1 & 1 & 1 & 1 & 1 \\
\hline Número de bebés por educador & 11 & 7 & 7 & 7 & 6 & 6 & 7 & 8 & 7 & 8 \\
\hline \multicolumn{11}{|l|}{ Instalações para atividades extras } \\
\hline Sala única & $\times$ & & $\times$ & $\times$ & & & & $\times$ & $\times$ & $x$ \\
\hline Espaço dormir reservado & & $\times$ & & & & $\times$ & & & & \\
\hline Espaço externo & & & & & $\times$ & & $\times$ & & & \\
\hline \multicolumn{11}{|l|}{ Disponibilidade de brinquedos nas salas } \\
\hline Bebé em contato constante com brinquedos & & & & & & $\times$ & & & & \\
\hline Brinquedos espalhados bebé sem contato & & $\times$ & & & $\times$ & & $\times$ & & & \\
\hline Sem brinquedos a vista & $\times$ & & $x$ & $x$ & & & & $x$ & $\times$ & $x$ \\
\hline \multicolumn{11}{|l|}{ Preocupações de educadores quanto ao cuidado do bebé } \\
\hline Desenvolvimento & & & & & $x$ & & & & & \\
\hline Higiene e Saúde & $\times$ & $\times$ & $x$ & $\times$ & $x$ & $x$ & $\times$ & $\times$ & $x$ & $x$ \\
\hline
\end{tabular}


Tabela 2

Contexto dos Berçários e Médias de Desempenho dos Bebés

\begin{tabular}{|c|c|c|c|c|c|c|c|}
\hline \multirow{4}{*}{$\begin{array}{l}\text { Características Contexto } \\
\text { (Berçários) }\end{array}$} & \multirow[b]{4}{*}{$n$} & \multicolumn{6}{|c|}{ Desempenho } \\
\hline & & \multicolumn{2}{|c|}{$\begin{array}{l}\text { Motricidade } \\
\text { Ampla }\end{array}$} & \multicolumn{2}{|c|}{$\begin{array}{l}\text { Motricidade } \\
\text { Fina }\end{array}$} & \multicolumn{2}{|c|}{$\begin{array}{l}\text { Linguagem e } \\
\text { Interação }\end{array}$} \\
\hline & & Pré & Pós & Pré & Pós & Pré & Pós \\
\hline & & $M$ & $M$ & $M$ & $M$ & $M$ & $M$ \\
\hline \multicolumn{8}{|l|}{ Nível de escolaridade dos educadores } \\
\hline Superior e Médio (B,D,E,F) & 4 & 3.44 & 4.07 & 3.65 & 4.00 & 3.42 & 3.83 \\
\hline Fundamental (A,C,G,H,I,J) & 6 & 2.75 & 3.69 & 2.88 & 4.49 & 3.17 & 3.47 \\
\hline \multicolumn{8}{|l|}{ Número de bebés por educador } \\
\hline Até 7 inclusive (B,C,D,E,F,G,I) & 7 & 3.23 & 3.92 & 3.85 & 4.19 & 3.52 & 3.83 \\
\hline Acima de $7(\mathrm{~A}, \mathrm{H}, \mathrm{J})$ & 3 & 3.00 & 3.65 & 2.83 & 4.50 & 2.50 & 3.00 \\
\hline \multicolumn{8}{|l|}{ Instalações para atividades extras } \\
\hline Sala e/ou espaço externo (E,F) & 2 & 3.63 & 4.63 & 3.67 & 4.37 & 3.17 & 4.10 \\
\hline Nenhuma (A,B,C,D,G,H,I,J) & 8 & 2.98 & 3.76 & 3.33 & 4.36 & 3.15 & 3.54 \\
\hline \multicolumn{8}{|l|}{ Disponibilidade de brinquedos nas salas } \\
\hline Espalhados ou contato (B,E,F,G) & 4 & 3.46 & 4.05 & 3.62 & 4.39 & 3.28 & 3.89 \\
\hline Nenhum Brinquedo (A,C,D,H,I,J) & 6 & 2.75 & 3.67 & 2.92 & 4.44 & 3.17 & 2.93 \\
\hline \multirow{2}{*}{$\begin{array}{l}\text { Escolas com condições adequadas ao } \\
\text { desenvolvimento }\end{array}$} & $M$ & 3.44 & 4.17 & 3.70 & 4.24 & 3.35 & 3.91 \\
\hline & $D P$ & 0.16 & 0.31 & 0.10 & 0.18 & 0.15 & 0.13 \\
\hline \multirow{2}{*}{$\begin{array}{l}\text { Escolas com condições pouco adequadas ao } \\
\text { desenvolvimento }\end{array}$} & $M$ & 2.87 & 3.69 & 2.99 & 4.45 & 3.00 & 3.23 \\
\hline & $D P$ & 0.14 & 0.05 & 0.23 & 0.06 & 0.33 & 0.31 \\
\hline
\end{tabular}

Nota: $n=$ distribuição dos bebés; $M=$ média; $D P=$ desvio padrão

Tabela 3

Desempenho dos Grupos Interventivo e Controle no Pré e Pós-teste

\begin{tabular}{|c|c|c|c|c|c|c|}
\hline \multirow{3}{*}{ Grupos } & \multicolumn{6}{|c|}{ Desempenho } \\
\hline & & \multicolumn{2}{|c|}{ Grupo Interventivo } & \multicolumn{2}{|c|}{ Grupo Controle } & \multirow[t]{2}{*}{$p$ grupos } \\
\hline & & $M$ & $D P$ & $M$ & $D P$ & \\
\hline \multicolumn{7}{|c|}{ Motricidade Ampla } \\
\hline Pré & & 2.96 & 0.59 & 2.89 & 1.19 & 0.74 \\
\hline \multirow[t]{2}{*}{ Pós } & & 4.45 & 0.14 & 2.83 & 1.16 & 0.01 \\
\hline & $p$ tempo & & 0.002 & & & \\
\hline \multicolumn{7}{|c|}{ Motricidade Fina } \\
\hline Pré & & 2.77 & 0.97 & 3.46 & 1.41 & 0.60 \\
\hline \multirow[t]{2}{*}{ Pós } & & 4.54 & 0.13 & 3.60 & 1.47 & 0.04 \\
\hline & $p$ tempo & & 0.003 & & & \\
\hline \multicolumn{7}{|c|}{ Integração e Linguagem } \\
\hline Pré & & 3.37 & 0.25 & 4.06 & 0.34 & 0.40 \\
\hline \multirow[t]{2}{*}{ Pós } & & 2.57 & 1.31 & 2.56 & 1.23 & 0.02 \\
\hline & $p$ tempo & & 0.007 & & & \\
\hline
\end{tabular}

Nota: $n=$ distribuição dos bebés; $M=$ médias; $D P=$ desvio padrão; $p=$ nível de significância 
A predisposição de educadores para propor atividades apropriadas ao desenvolvimento, especialmente em situações de risco em escolas públicas, característica do presente estudo, depende do nível de escolaridade dos educadores (Moreira, Silveira \& Andreoli, 2009). O pouco conhecimento sobre o desenvolvimento humano (Almeida et al., 2005; Hungerford \& Cox, 2006); as oportunidades limitadas de frequentarem cursos de formação continuada e aperfeiçoamento (Freitas \& Castro, 2003), consequência das restrições económicas (Zulian \& Freitas, 2001), repercutem negativamente na qualidade dos serviços prestados pelos educadores nas escolas.

No que se refere à rotina dos educadores no presente estudo, similar a estudos prévios (Besharov \& Marrow, 2006; Moreira et al., 2009), constatou-se que quanto maior o número de bebés por educador menor atenção individualizada era propiciada. Semelhante a estudo prévio (Almeida et al., 2005), os educadores do presente estudo não conseguiam ter momentos livres para brincar com os bebés e realizar atividades lúdicas em decorrência das demandas de higiene, alimentação e limpeza (Almeida et al., 2005). A falta de pessoal no dia-a-dia dos berçários dificulta a integração educador-bebé, limitando o desenvolvimento do mesmo (Almeida et al., 2005; Marques et al., 2007).

As instalações eram, em geral, inadequadas ao desenvolvimento infantil (Almeida et al., 2005; Bronfenbrenner, 2005). Sem a possibilidade de movimentar-se em espaço mais amplo, o que seria possível com uma sala para brincar, as interações do bebé com seus pares e a descoberta do ambiente se tornavam restritas (Almeida et al., 2005; Besharov \& Marrow, 2006; Vasconcelos et al., 2003). A estrutura física interfere na rotina dos berçários, e a restrição dos bebés à somente uma sala por até 8 horas por dia não é apropriado ao desenvolvimento, interferindo no sono, através das observações e dos relatos das educadoras, e nas oportunidades de exploração dos participantes (Almeida et al., 2005).
No presente estudo, congruente com estudo prévio (Almeida et al., 2005), as oportunidades de manipular brinquedos eram reservadas às crianças que caminhavam ou se deslocavam com facilidade. Os demais bebés passavam grande parte do tempo nos berços e em carrinhos, sendo que, os mesmos, se envolviam sozinhos em atividades manipulativas dos brinquedos disponíveis e na manipulação do próprio corpo. Brinquedos adequados a esta faixa etária, como por exemplo: móbiles, jogos de encaixar, abrir, fechar e descobrir não foram encontrados em nenhuma escola. Brinquedos e atividades lúdicas são essenciais ao processo de construção de significados por parte do bebé, pois, a partir da novidade destas relações entre o bebé, o educador e seus brinquedos, ele explora e integra novos conhecimentos (Vasconcelos et al., 2003).

\section{A intervenção no contexto dos berçários}

O programa interventivo oportunizou experiências em tarefas de ajustes posturais, equilíbrio e deslocamento, favorecendo a motricidade ampla. As atividades de controle postural auxiliaram na interação de múltiplos sistemas neurais, para maior controle postural, favorecendo desempenhos motores amplos mais sofisticados e a liberação das mãos para a manipulação de diferentes brinquedos (Almeida et al., 2005, 2008). A rotina das escolas não priorizava o cuidado do bebé em diferentes posturas e deslocamentos; esta limitação do meio físico dos berçários restringe as possibilidades de efetiva exploração (Almeida et al., 2005), com consequente repercussão negativa no desenvolvimento. No entanto, outro estudo realizado com bebés de berçário nas mesmas condições financeiras (Almeida, 2010), mostrou uma rotina em que o bebé ficava mais exposto ao chão, priorizando experiências de ganhos posturais e deslocamentos. Permitiam, também, exploração dos bebés ao meio e aos brinquedos de motricidade fina e ampla, segundo classificação de Gabbard e Rodrigues (2007). Neste mesmo estudo, quando comparado com bebés de abrigos e os que passavam 
parte do dia em casa com suas mães, os bebés do berçário eram mais desenvolvidos (Almeida, 2010). Quanto a mudanças positivas e significativas nas atividades de integração e linguagem, as quais envolveram a emissão de sons, brincadeiras e jogos corporais, as mesmas são decorrentes, possivelmente, da interação oral e motivacional constante do examinador com o bebé (Almeida et al., 2005). Destaca-se que conversas e outras formas de interação oral não faziam parte da rotina do educador com os bebés do berçário. Enquanto realizava os 15 minutos de intervenção, o bebé produzia sons guturais, vocalizações e sorrisos, recebendo respostas estimuladoras de reciprocidade $\mathrm{e}$ afetividade do pesquisador, essas estratégias de interação e de motivação (Almeida et al., 2005; Valentini, 2002, 2004; Valentini \& Rudsill, 2004) repercutiram favoravelmente para fortalecer os vínculos afetivos e possibilitar o desenvolvimento de novas habilidades. Algumas tarefas de reação ao som e sensibilidade visual, contidas no instrumento avaliativo, foram nas quais os grupos interventivo e controle mais se assemelharam, provavelmente em decorrência da natureza destas atividades. $\mathrm{O}$ dia-a-dia do berçário é repleto de barulhos e presença de estímulos visuais provindos de todas as direções, aos quais os bebés podem ser mais fortemente expostos se não ficarem restritos a um único espaço físico. Na tarefa de perseguição visual, os bebés mais velhos interessavam-se por pegar logo o brinquedo, explorando os mesmos com as mãos e a boca; enquanto os bebés mais jovens permaneciam na tarefa observando o objeto. Nas atividades de manipulação e reconhecimento da função específica dos brinquedos, os bebés do grupo interventivo passaram a compreender rapidamente a função da tarefa, repetindo a mesma diversas vezes. O desenvolvimento manipulativo foi garantido em grande parte pelo aumento da capacidade de controle de tronco e sedestação livre, favorecendo a concentração do bebé no brinquedo (Goubet et al., 2006; Rocha et al, 2006).
Concluindo, ressalta-se a necessidade de melhorar a qualidade da rotina dos berçários que atendem crianças provenientes de classes desfavorecidas socioeconomicamente. Estratégias simples como organizar horários para passeios no pátio; momentos para brincar; alimentação individualizada para fortalecer a interação com o educador; e ambientes separados para sono e brinquedo são necessários nas escolas investigadas. Ainda mais, sugere-se o oferecimento constante de brinquedos de diferentes tamanhos, cores, formatos e funções, para que se diversifiquem as possibilidades de exploração do bebé do meio em que está inserido e que os mesmos permaneçam ao alcance das crianças.

O conhecimento sobre a importância das experiências para o bebé parecia muito distante da realidade do educador; os quais passavam envolvidos com as necessidades de higiene e alimentação dos bebés, contrariando a atual Política Nacional de Educação Infantil Brasileira (Ministério da Educação e do Desporto, Secretaria de Educação Fundamental do Brasil (1998), que enfatiza a necessidade de considerar o processo de desenvolvimento do ser humano como um todo. Envolver os educadores efetivamente no processo de propiciar experiência de aprendizagem pode resultar na implementação de uma rotina mais adequada ao desenvolvimento do bebé.

\section{CONCLUSÕES}

A intervenção individualizada, mesmo que breve, como no presente estudo, pode favorecer o desenvolvimento integral das crianças e pode ser facilmente incorporada na rotina do berçário. A capacitação de educadoras, que repercutam em práticas mais adequadas ao desenvolvimento integral do bebé, complementando a educação familiar, deve ser primordial no processo de garantir cuidados adequados. As capacitações podem ocorrer através de parcerias com municípios e universidades, uma vez que estas escolas não têm meios de promover treinamentos. O processo de desenvolvimento humano deve ser o foco de treinamen- 
tos quando se aspira implementar propostas educativas que desafiem a cognição e a motricidade de bebés, possibilitando o aumento das interações sociais e consequente desenvolvimento adequado. Sugere-se que futuras pesquisas investiguem as condições do contexto familiar dessas crianças e criem propostas de intervenção para os educadores, limitação do presente estudo. O ideal seria realizar um estudo longitudinal que acompanhasse esses bebés para verificar qual a repercussão do estudo nas aquisições das suas habilidades, como a marcha, por exemplo, limitação do presente estudo.

Agradecimentos:

Nada a declarar.

\section{Conflito de Interesses:}

Nada a declarar.

Financiamento:

Nada a declarar.

\section{REFERÊNCIAS}

Adalbjornson, C. (2001). The effects of an interactive tracking skill intervention on infant's motor and cognitive skills. Dissertação de Doutorado, Universidade de Auburn, Auburn, Alabama, USA.

Almeida, C. S. (2010). O impacto de um programa de intervenção motora participativa ampliando oportunidades de desenvolvimento em bebês de até dezoito meses em três contextos diferentes. Tese de Doutorado, Universidade Federal do Rio Grande do Sul, Porto Alegre, Rio Grande do Sul, Brasil.

Almeida, C. S., Paines, A. V. \& Almeida, C. B. (2008). Intervenção motora precoce ambulatorial para neonatos prematuros no controle postural. Revista Ciência \& Saúde, 1(2), 64-70.

Almeida, C. S., Valentini, N. C., \& Lemos, C. X. G. (2005). A influência de um programa de intervenção motora no desenvolvimento de bebês em berçários de baixa renda. Temas Sobre Desenvolvimento, 83, 40-48.
Besharov, D. J., \& Marrow, J. S. (2006). Introdution: rethinking child care research. Evaluation Review, 30(5), 539-555. doi: 10.1177/0193841 X06291522

Bronfenbrenner, U. (2005). The bioecological theory of human development. In U. Bronfenbrenner (Ed), Making human beings human: bioecological perspectives on human development (pp. 3-15). California: Sage.

Carvalhares, M. A. B., \& Benício, M. H. D. (2002). Capacidade materna de cuidar e desnutrição infantil. Revista de Saúde Pública, 36, 188-197. doi: 10.1590/S0034-89102002000200011

Departamento Intersindical de Estatística e Estudos Socioeconômicos (2007). Anuário dos trabalhadores ( $\left.8^{\mathrm{a}} \mathrm{ed}\right)$. São Paulo: Autor.

Freitas, S. N. \& Castro, S. F. (2003). Representação social e educação especial: A representação dos professores de alunos com necessidades educativas especiais incluídos na classe comum do ensino regular. Recuperado em 20 de agosto de 2004, de http://www.educacaoonline.pro.br/art_rs_e_ed ucacao_especial.asp

Gabbard, C, \& Rodrigues, L. (2007). Affordances for motor development. In: Krebs, R., \& Neto, C. (Ed), Tópicos em desenvolvimento motor na infância e adolescência. Rio de Janeiro: LECSU.

Goubet, N., Rochat, P., Maire-Leblond, C., \& Poss, S. (2006). Learning from others in 9-18 monthold infants. Infant and Child Development, 15(2), 161-177. doi: 10.1002/icd.446

Hungerford, A., \& Cox, M. J. (2006). Family factors in child care research. Evaluation Review, 30, 631-655. doi: 10.1177/0193841X06291532

Instituto Brasileiro de Geografia e Estatística (2010). Sistema IBGE de recuperação automáticaSIDRA: Censo demográfico. Recuperado em 20 de maio de 2012, de: http://www.censo2010. ibge.gov.br/

Marques, E. P. P., Pelicioni, M. C. F., \& Pereira, I. M. T. B. (2007). Educação pública: falta de prioridade do poder público ou desinteresse da sociedade? Revista Brasileira do Crescimento e Desenvolvimento Humano, 17(3), 8-20.

Ministério da Educação e do Desporto, Secretaria de Educação Fundamental do Brasil (1998). Referencial curricular nacional para a educação infantil. Brasília: MEC/SEF.

Moreira, F. G., Silveira, D. X., \& Andreoli, S. B. (2009). Conhecimentos e atitudes de educadores de escolas públicas na prevenção do uso indevido de drogas. Revista Brasileira de 
Psiquiatria, 31 (2), 10-29. doi: 10.1590/S151644462009000200003

Müller, A. B. (2008). Efeitos da intervenção motora em diferentes contextos no desenvolvimento da criança com atraso motor. Dissertação de Mestrado, Universidade Federal do Rio Grande do Sul, Porto Alegre, Rio Grande do Sul, Brasil.

Pinto, E. B., Vilanova, L. C. P., \& Vieira, R. M. (1997). O Desenvolvimento do comportamento da criança no primeiro ano de vida: Padronização de uma escala para a avaliação e o acompanhamento. São Paulo: Casa do Psicólogo/FAPESP.

Rocha, N. A. C. F., Silva, F. P. S., \& Tudella, E. (2006). Influência do tamanho e da rigidez dos objetos nos ajustes proximais e distais do alcance de lactentes. Revista Brasileira de Fisioterapia, 10(3), 263-269.

Spessato, B. C., Valentini, N. C. \& Krebs, R. J. (2009). Educação infantil e intervenção motora: Um olhar a partir da teoria bioecológica de Bronfenbrenner. Movimento, 15, 149-176.

St.Pierre, R. G., \& Rossi, P. H. (2006). Randomize groups, not individuals: A strategy for improving early childhood programs. Evaluation Review,
30(5), 656-685. doi: 10.1177/0193841X0629 1533

Valentini, N. C. (2002). A influência de uma intervenção motora no desempenho motor e na percepção de competência de crianças com atrasos motores. Revista Paulista de Educação Física, 16(1), 61-75.

Valentini, N. C. (2004). Visual cues, verbal cues and child development. Strategies, 17(3), 21-23.

Valentini, N. C., \& Rudsill, M. E. (2004). Motivational climate, motor-skill development, and perceived competence: Two studies of developmentally delayed Kindergarten children. Journal of Teaching Physical Education, 23, 216-234.

Vasconcelos, C. R. F., Aorim, K. S., Anjos, A. M., \& Ferreira, M. C. R. (2003). A incompletude como virtude: interação de bebês na creche. Psicologia: Reflexão e Crítica, 16(2), 18-32. doi: 10.1590/S0102-79722003000200009

Zulian, M. S \& Freitas, S. N. (2001). Formação de professores na educação inclusiva: Aprendendo a viver, criar, pensar e ensinar de outro modo. Revista Educação Especial, 18, 47-57

(c) EY-No Todo o conteúdo da revista Motricidade está licenciado sob a Creative Commons, exceto quando especificado em contrário e nos conteúdos retirados de outras fontes bibliográficas. 